\title{
Velocity Control Based on Active Disturbance Rejection for Air-Breathing Supersonic Vehicles
}

\author{
Chao Ming, ${ }^{1}$ Ruisheng Sun $\left({ }^{D},{ }^{2}\right.$ and Xiaoming Wang ${ }^{1}$ \\ ${ }^{1}$ School of Mechanical Engineering, Nanjing University of Science and Technology, Nanjing 210094, China \\ ${ }^{2}$ School of Energy and Power Engineering, Nanjing University of Science and Technology, Nanjing 210094, China \\ Correspondence should be addressed to Ruisheng Sun; srscom@163.com
}

Received 25 February 2018; Accepted 17 April 2018; Published 17 May 2018

Academic Editor: Yimin Zhou

Copyright (c) 2018 Chao Ming et al. This is an open access article distributed under the Creative Commons Attribution License, which permits unrestricted use, distribution, and reproduction in any medium, provided the original work is properly cited.

\begin{abstract}
This paper investigates a velocity tracking control approach for air-breathing supersonic vehicles with uncertainties and external disturbances. Considering angle of attack is difficult to be precisely measured in practice, extended state observer technique is introduced into the state reconstruction design. In order to avoid possible oscillations in the design of the traditional extended state observer (TESO), a modified extended state observer (MESO) is developed, where a new smooth function is proposed to replace nonsmooth function of TESO. On the basis of it, an active disturbance rejection controller (ADRC) is designed for velocity control systems. Simultaneously, the closed-loop stability is rigorously proved by using Lyapunov theory. Finally, numeric simulations are conducted to validate the effectiveness of the proposed method.
\end{abstract}

\section{Introduction}

Air-breathing supersonic vehicles (ASV) are becoming crucial in recent decades because they may provide a feasible and cost-efficient access to space for both civilian and military applications [1]. In comparison to traditional rocket propulsion weapon systems, ASV represents a series of advantages of higher payload capacity, lower flight cost, and rapid global precision strike capability. However, most ASV adopt the design of airframe integrated with scramjet engine configuration [2], which leads to strong couplings between the flight attitude and propulsion. For instance, the compression of the flow through the scramjet engine inlet depends on the characteristic of the bow shock wave under the vehicle fore-body, which is mainly up to the angle of attack (AOA). In addition, the dynamic model built by using aerodynamic experiments is usually imprecise due to the unmodelled dynamics and external disturbances in practice. Thus, the control design of such flight control systems is a challenging issue due to its high nonlinearities, strong couplings, and significant uncertainties.

In recent decades, plenty of control strategies have also been explored for air-breathing hypersonic vehicles (AHV), for example, feedback linearization [3], backstepping [4], adaptive control $[5,6]$, and sliding mode control (see $[7,8]$ and references therein). Generally speaking, feedback linearization is an effective means to analyse stability of the nonlinear system, and it was used to design AHV control system in [3]. However, the feedback linearization excessively depends on the accurate information of the dynamic model, and it cannot deal with the unknown changes of the dynamic system. Additionally, a backstepping control scheme is proposed by combining the dynamic surface control technique in [4], but there still exist the fatal shortcomings of "explosion of term" in the backstepping design, because of the repetitive computation of differentiation for virtual control laws. From $[5,6]$, adaptive control technique has provided a new way to design the control system. However, adaptive controllers always have overly complicated computation and the unknown parameters of system need to be recognized online, which cannot be implemented in engineering. Among previous control approaches, sliding model control (SMC) attracts extensive attention due to its simplicity and robustness to parameter uncertainties and external disturbances $[7,8]$. Unfortunately, there are also some disadvantages in SMC, and the well-known one is chattering phenomenon, which limits application of SMC in the AHV control system. 
It is worthwhile to mention that the active disturbance rejection controller (ADRC) has been well developed as an effective robust control strategy to achieve satisfactory performance for nonlinear systems with uncertainties and external disturbances $[9,10]$. Compared with the methods mentioned above, ADRC does not depend on the accurate information of unknown dynamic model. It can retain better static and dynamic performances and stronger robustness and adaptability, where a nonlinear control strategy is designed by estimating and compensating the internal and external disturbances in real time. Thus, the ADRC is widely applied in industrial control, for example, motion control [11, 12], microelectromechanical gyroscopes [13, 14], wind energy system $[15,16]$, and robot control $[17,18]$. In recent research, the concept of ADRC has also been applied in the field of AHV [19-21]. Reference $[19,20]$ presented ADRC control schemes for AHV attitude tracking control system. Based on this work, a novel ADRC approach was designed for hypersonic vehicle attitude tracking system by introducing trajectory linearization control technique in [21]. In all these attitude system control designs for AHV, there are two aspects of issues. One is that AOA is assumed to be precisely measurable. In practice, AOA is unfortunately difficult to be measured. The other is that in the framework of ADRC the extended state observer (ESO) is used to estimate the lumped uncertainties without any parametric condition $[22,23]$, and estimation error can converge to zero in the specified condition. Nevertheless, the traditional ESO (TESO) is not able to obtain high precision and enough smooth response because the general nonlinear function used in TESO is nonderivable at the dividing point. Consequently, there is a potential unsatisfactory chattering phenomenon in the estimated dynamics if the width of fraction is fairly small [24].

In terms of these two issues, the objective of this paper is to further study the ADRC design for nonlinear ASV velocity systems subject to parameter uncertainties, external disturbances, and immeasurable AOA. Firstly, we investigate a MESO by introducing a new smooth function to obtain more precise estimation of lumped unknown dynamics. Then considering the AOA cannot be measured directly, the MESObased reconstruction design of $\mathrm{AOA}$ is conducted in the ADRC velocity systems, and the closed-loop system stability is also proved based on Lyapunov theory. Finally, extensive simulations are conducted to verify the performance of the proposed control method.

The remainder of this paper is organized as follows. Section 2 describes the longitudinal dynamic model of ASV and states the problem formulation and some preliminaries. In Section 3, a MESO is developed by using a new smooth function and the MESO convergence is analysed. In Section 4, the ADRC-based controller is designed in detail and the closed-loop system stability is also proved. Comparative simulations are conducted in Section 5 and some conclusions are involved in Section 6.

\section{Problem Formulation}

This paper will investigate the velocity control design for air-breathing supersonic vehicle systems. A typical velocity

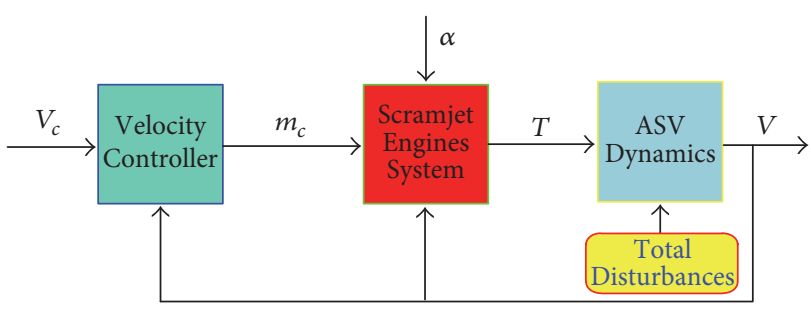

FIGURE 1: Velocity control process of ASV systems.

control process of nonlinear air-breathing supersonic vehicle systems can be given in Figure 1. The task of the velocity controller is to calculate the control $m_{c}$ (i.e., fuel mass flow) in terms of the desired velocity command $V_{c}$ (i.e., control input) and current velocity $V$. The thrust force $T$ is produced by the scramjet engine system, which can be decided by the velocity, fuel mass flow, and angle of attack $\alpha$. The current velocity is measured by inertial navigation system while angle of attack is not precisely measurable in practice. Thus it is essential to reconstruct the angle of attack by using the measurable attitude, which will be discussed in the next section.

With design simplification and without loss of generality, we only consider the longitudinal dynamics of ASV here. The nonlinear dynamics can be described by a set of differential equations in terms of velocity $V$, flight-path angle $\theta$, altitude $h$, angle of attack $\alpha$, pitch rate $\omega_{z}$, and vehicle mass $m$, respectively. Define the state vector $\left[x_{1}, x_{2}, x_{3}, x_{4}\right]=\left[V, \theta, \alpha, \omega_{z}\right]$, and the nonlinear dynamics can be written in a state-space form [25] as follows:

$$
\begin{aligned}
& \dot{x}_{1}=f_{1}+g_{1} m_{c}+d_{t} \\
& \dot{x}_{2}=f_{2} \\
& \dot{x}_{3}=x_{4}-f_{2} \\
& \dot{x}_{4}=f_{4}+g_{4} \delta_{z} .
\end{aligned}
$$

Here

$$
\begin{aligned}
& f_{1}=\frac{\left(q S C_{T 0} \cos \alpha-D\right)}{m}-g \sin \theta, \\
& g_{1}=\frac{q S C_{T}^{m_{c}} \cos \alpha}{m}, \\
& f_{2}=\frac{(T \sin \alpha+L)}{m V}+g \frac{\cos \theta}{V}, \\
& f_{4}=\frac{\left[q S l\left(C_{M}^{\alpha} \alpha+C_{M}^{\omega_{z}} \omega_{z}\right)\right]}{J_{z}}, \\
& g_{4}=\frac{q S l C_{M}^{\delta_{z}}}{J_{z}},
\end{aligned}
$$

where $g, J_{z}$ represent the acceleration of gravity and the moment of inertia, respectively; fuel mass flow $m_{c}$ is the control; $d_{t}$ means the total disturbance of velocity system. The 
lift $L$, drag $D$, thrust force $T$, and pitching moment $M_{z}$ can be formulated as

$$
\begin{aligned}
L & =q S C_{L} \\
D & =q S C_{D} \\
T & =q S C_{T} \\
M_{z} & =q S l\left(C_{M}^{\alpha} \alpha+C_{M}^{\omega_{z}} \omega_{z}+C_{M}^{\delta_{z}} \delta_{z}\right),
\end{aligned}
$$

where dynamic pressure $q=0.5 \rho V^{2}$, and $S$ and $l$ denote reference area and length, respectively. $\rho$ is density of air; $C_{L}$, $C_{D}$, and $C_{T}$ define the lift, drag, and thrust force coefficient, separately. $C_{M}^{\alpha}, C_{M}^{\omega_{z}}$, and $C_{M}^{\delta_{z}}$ represent the moment coefficient due to the angle of attack, pitch rate, and deflection of the control surface $\delta_{z}$, respectively. Here, $C_{L}$ and $C_{D}$ are usually obtained by wind tunnel test.

Owing to the couplings between the aerodynamic force and the propulsion system, a precise curve-fitted approximation of thrust coefficient is expressed as

$$
C_{T}=C_{T}^{m_{c}}(h, \mathrm{Ma}, \alpha) \cdot m_{c}+C_{T 0}(h, \mathrm{Ma}, \alpha),
$$

where the coefficients $C_{T}^{m_{c}}$ and $C_{T 0}$ depend on the altitude $h$, Mach number $\mathrm{Ma}$, and $\alpha$.

Meanwhile, the parameter uncertainties and external disturbance are considered in this study, and the parametric uncertainties are depicted as a perturbation $\Delta$ to its nominal values; that is,

$$
\begin{gathered}
C_{D}=C_{D 0}\left(1+\Delta C_{D}\right) \\
\rho=\rho_{0}(1+\Delta \rho),
\end{gathered}
$$

where subscript 0 denotes the nominal value. The total disturbance $d_{t}$ is unknown and bounded with the parameter uncertainties and external disturbances $d$ in the velocity system, which is expressed as

$$
d_{t}=-\frac{S V^{2}}{2 m}\left(\rho_{0} \Delta C_{D}+C_{D 0} \Delta \rho+\Delta \rho \Delta C_{D}\right)+d .
$$

\section{Modified ESO Design}

In this section, MESO is developed based on a new smooth function to prevent undesirable chattering phenomenon in TESO, and the MESO will be employed to address the unknown lumped dynamics and the unmeasured AOA. The design of MESO can be processed as follows.

To begin, the concept of the traditional ESO is presented, and an $n$th order nonlinear dynamic system is considered as

$$
z^{(n)}=f\left(z, \dot{z}, \ldots, z^{(n-1)}, w\right)+b u
$$

where $f(\cdot)$ is the function of the system states $z$ and unknown disturbance $w$.
By introducing an extended state $z_{n+1}$, system (7) can be rewritten in a state-space form; that is,

$$
\begin{gathered}
\dot{z}_{1}=z_{2} \\
\dot{z}_{2}=z_{3} \\
\vdots \\
\dot{z}_{n}=z_{n+1}+b u \\
\dot{z}_{n+1}=\dot{w} \\
y=z_{1},
\end{gathered}
$$

where the uncertain item $\dot{w}$ is unknown and bounded. Consequently, we can estimate the uncertain item by using state observer technique, which is defined as follows:

$$
\begin{gathered}
\dot{\vec{z}}_{1}=\widehat{z}_{2}+\beta_{01} g_{1}\left(e_{1}\right) \\
\dot{\widehat{z}}_{2}=\widehat{z}_{3}+\beta_{02} g_{2}\left(e_{1}\right) \\
\vdots \\
\dot{\vec{z}}_{n}=\widehat{z}_{n+1}+\beta_{0 n} g_{n}\left(e_{1}\right)+b u \\
\dot{\vec{z}}_{n+1}=\beta_{0 n+1} g_{n+1}\left(e_{1}\right),
\end{gathered}
$$

where $e_{1}=y-\widehat{z}_{1}$ is observer output error, and $\widehat{z}_{n+1}$ is estimation value of the unknown disturbance. $\beta_{0 i}$ is the $i$ th observer gain and $g_{i}\left(e_{1}\right)$ represents a set of suitably constructed nonlinear functions satisfying $e_{1} g_{i}\left(e_{1}\right)>0, \forall e_{1} \neq 0$ and $g_{i}(0)=0$. If the nonlinear functions $g_{i}(\cdot)$ and the related parameters are chosen properly, the estimated state variables $\widehat{z}_{i}$ are expected to converge to the respective states of the system $z_{i}$; that is, $\widehat{z}_{i} \rightarrow z_{i}, i=1,2, \ldots, n+1$.

Obviously, the nonlinear function is crucial for the design of ESO [26], and it can be expressed as

$$
\mathrm{fal}\left(e_{1}, a, \delta\right)= \begin{cases}e_{1} \delta^{a-1} & \left|e_{1}\right| \leq \delta \\ \left|e_{1}\right|^{a} \operatorname{sgn}\left(e_{1}\right) & \left|e_{1}\right|>\delta,\end{cases}
$$

where $\delta>0$ and $0<a<1$.

It is easily seen that $\mathrm{fal}\left(e_{1}, a, \delta\right)$ is not derivable in the dividing point $\pm \delta$. Furthermore, if $\delta$ is too small, the derivative of function $\mathrm{fal}\left(e_{1}, a, \delta\right)$ will become nonsmooth, which will degrade the performance of the system and even seriously trigger divergent phenomenon.

Consequently, it is imperative to find a smooth and derivable function $\mathrm{fal}_{2}\left(e_{1}, a, \delta\right)$ to replace the traditional fal $\left(e_{1}\right.$, $a, \delta)$, and the modified function $\mathrm{fal}_{2}\left(e_{1}, a, \delta\right)$ is depicted as follows.

When $\left|e_{1}\right|>\delta, \operatorname{fal}_{2}\left(e_{1}, a, \delta\right)$ is same as (10) such that

$$
\mathrm{fal}_{2}\left(e_{1}, a, \delta\right)=\left|e_{1}\right|^{a} \operatorname{sgn}\left(e_{1}\right) .
$$

When $\left|e_{1}\right|<\delta$, we choose

$$
\mathrm{fal}_{2}\left(e_{1}, a, \delta\right)=p e_{1}+q e_{1}^{2}+r\left(1-\exp \left(e_{1}\right)\right)
$$


subject to

$$
\begin{aligned}
& \mathrm{fal}_{2}\left(e_{1}, a, \delta\right)=\delta^{a} \quad e_{1}=\delta \\
& \mathrm{fal}_{2}\left(e_{1}, a, \delta\right)=-\delta^{a} \quad e_{1}=-\delta \\
& \mathrm{fal}_{2}^{\prime}\left(e_{1}, a, \delta\right)=a \delta^{a-1} \quad e_{1}=\delta,-\delta,
\end{aligned}
$$

where (13) can guarantee that (12) is smoothly convergent to zero; $\exp (\cdot)$ is the exponential function based on the natural constant $e$.

Substituting (12) into (13), then we can obtain that

$$
\begin{aligned}
& p \\
& =\frac{\delta^{a-1}(2-4 \cdot \exp (\delta)+2 \cdot \exp (2 \delta)+a+2 \delta-a \cdot \exp (2 \delta))}{2 \delta+\exp (2 \delta)-4 \cdot \exp (\delta)+3} \\
& q=\frac{\delta^{a-2}(1-a) \cdot(\exp (\delta)-1)^{2}}{2 \delta+\exp (2 \delta)-4 \cdot \exp (\delta)+3} \\
& r=\frac{-2 \delta^{a} \cdot \exp (\delta) \cdot(a-1)}{2 \delta+\exp (2 \delta)-4 \cdot \exp (\delta)+3} .
\end{aligned}
$$

Then, we analyse the convergence of the general secondorder MESO based on the self-stable region method [27] by introducing the following lemmas.

Lemma 1. In terms of the defined observer estimation errors $e_{1}=z_{1}-\widehat{z}_{1}, e_{2}=z_{2}-\widehat{z}_{2}$ and (8)-(9), the MESO errors are modelled as

$$
\begin{aligned}
& \dot{e}_{1}=e_{2}-\beta_{01} g_{1}\left(e_{1}\right) \\
& \dot{e}_{2}=w(t)-\beta_{02} g_{2}\left(e_{1}\right),
\end{aligned}
$$

where $\beta_{01}, \beta_{02}$ are the observer gain.

Define the function $h_{c}\left(e_{1}, e_{2}\right)=e_{2}-\beta_{01} g_{1}\left(e_{1}\right)+$ $k f_{c}\left(e_{1}\right) \operatorname{sgn}\left(e_{1}\right)$, where $f_{c}\left(e_{1}\right)$ is a positive definite function, $f_{c}(0)=0, k>1$ is a constant. Then, the self-stable region of system (15) is the region $G=\left\{\left(e_{1}, e_{2}\right):\left|h_{c}\left(e_{1}, e_{2}\right)\right| \leq f_{c}\left(e_{1}\right)\right\}$.

Proof. Assume $\left(e_{1}, e_{2}\right)$ remains in the region $G$ after time $T$; that is, the condition $\left(e_{1}(t), e_{2}(t)\right) \in G$ is established in terms of $\forall t>T$. Meanwhile, according to the construction of the region $G$, we can obtain that

$$
\begin{aligned}
& -k f_{c}\left(e_{1}\right) \operatorname{sgn}\left(e_{1}\right)-f_{c}\left(e_{1}\right) \leq e_{2}-\beta_{01} g_{1}\left(e_{1}\right) \\
& \leq-k f_{c}\left(e_{1}\right) \operatorname{sgn}\left(e_{1}\right)+f_{c}\left(e_{1}\right) .
\end{aligned}
$$

Introduce the function $V_{1}$ as follows:

$$
V_{1}=\frac{1}{2} e_{1}^{2} \text {. }
$$

The time derivative of $V_{1}$ is conducted as

$$
\begin{aligned}
\dot{V}_{1} & =e_{1} \dot{e}_{1}=e_{1}\left(e_{2}-\beta_{01} g_{1}\left(e_{1}\right)\right) \\
& \leq-(k-1) f_{c}\left(e_{1}\right)\left|e_{1}\right| .
\end{aligned}
$$

As $k>1, f_{c}\left(e_{1}\right)>0$, we can obtain

$$
\dot{V}_{1}<0 \text {. }
$$

Then the conditions $e_{1}(t) \rightarrow 0(t \rightarrow \infty)$ and $e_{2}(t) \rightarrow$ $0(t \rightarrow \infty)$ hold. Thus, the region $G$ is the self-stable region of system (15). This completes the proof.

Lemma 2. In terms of system (15), if the inequation $\beta_{01}^{2} g_{1}^{\prime}>$ $4 \beta_{02}\left|\left(g_{2} / g_{1}^{\prime}\right)^{\prime}\right|$ holds, the error of the observer will converge to zero when $w(t)=0$, and $g_{1}\left(e_{1}\right)$ is a strictly increasing function; that is, $e_{1}(t) \rightarrow 0, e_{2}(t) \rightarrow 0(t \rightarrow \infty)$, where $g^{\prime}=d g / d e_{1}$.

Proof. (1) For $\left(e_{1}(t), e_{2}(t)\right)$, which is in the self-stable region $G=\left\{\left(e_{1}, e_{2}\right):\left|h_{c}\left(e_{1}, e_{2}\right)\right| \leq f_{c}\left(e_{1}\right)\right\}$, the error of the observer will converge to zero; that is, $e_{1}(t) \rightarrow 0, e_{2}(t) \rightarrow 0(t \rightarrow \infty)$ based on Lemma 1.

(2) For $\left(e_{1}(t), e_{2}(t)\right)$, which is out of the self-stable region $G$, for example, $\left(e_{1}, e_{2}\right)$ is satisfied with $\left|h_{c}\left(e_{1}, e_{2}\right)\right|>f_{c}\left(e_{1}\right)$.

Introduce the function $V_{2}$ as follows:

$$
V_{2}=\frac{1}{2}\left(h_{c}^{2}\left(e_{1}, e_{2}\right)-f_{c}^{2}\left(e_{1}\right)\right) .
$$

The time derivative of $V_{2}$ is conducted as

$$
\begin{aligned}
\dot{V}_{2}= & h_{c}\left(e_{1}, e_{2}\right) \dot{h}_{c}-f_{c}\left(e_{1}\right) \dot{f}_{c}\left(e_{1}\right) \\
= & h_{c}\left(\dot{e}_{2}+\frac{\partial h_{c}}{\partial e_{1}} \dot{e}_{1}\right)-f_{c} \frac{\mathrm{d} f_{c}}{\mathrm{~d} e_{1}} \dot{e}_{1} \\
= & h_{c}\left[-\beta_{02} g_{2}+\frac{\partial h_{c}}{\partial e_{1}}\left(h_{c}-k f_{c} \operatorname{sgn}\left(e_{1}\right)\right)\right] \\
& -f_{c} \frac{\mathrm{d} f_{c}}{\mathrm{~d} e_{1}}\left(h_{c}-k f_{c} \operatorname{sgn}\left(e_{1}\right)\right) \\
= & h_{c}\left[\frac{\partial h_{c}}{\partial e_{1}} h_{c}-\left(\beta_{02} \frac{\left|g_{2}\right|}{f_{c}}+k \frac{\partial h_{c}}{\partial e_{1}}\right) f_{c} \operatorname{sgn}\left(e_{1}\right)\right] \\
& -f_{c} \frac{\mathrm{d} f_{c}}{\mathrm{~d} e_{1}} h_{c}+k f_{c} \frac{\mathrm{d} f_{c}}{\mathrm{~d} e_{1}} f_{c} \operatorname{sgn}\left(e_{1}\right) .
\end{aligned}
$$

Select the function $f_{c}\left(e_{1}\right)$ as

$$
f_{c}\left(e_{1}\right)=\frac{\beta_{02}\left|g_{2}\left(e_{1}\right)\right|}{k \beta_{01} g_{1}^{\prime}\left(e_{1}\right)}
$$

Hence

$$
\begin{aligned}
\beta_{02} \frac{\left|g_{2}\right|}{f_{c}}+k \frac{\partial h_{c}}{\partial e_{1}}= & k \beta_{01} g_{1}^{\prime} \\
& +k\left(-\beta_{01} g_{1}^{\prime}+k \frac{\mathrm{d}\left(f_{c} \operatorname{sgn}\left(e_{1}\right)\right)}{\mathrm{d} e_{1}}\right) \\
= & k^{2} \frac{\mathrm{d}\left(f_{c} \operatorname{sgn}\left(e_{1}\right)\right)}{\mathrm{d} e_{1}} .
\end{aligned}
$$


Substituting (23) into (21) yields

$$
\begin{aligned}
\dot{V}_{2}= & h_{c}\left(\frac{\partial h_{c}}{\partial e_{1}} h_{c}-k^{2} \frac{\mathrm{d}\left(f_{c} \operatorname{sgn}\left(e_{1}\right)\right)}{\mathrm{d} e_{1}} f_{c} \operatorname{sgn}\left(e_{1}\right)\right) \\
& -f_{c} \frac{\mathrm{d} f_{c}}{\mathrm{~d} e_{1}} h_{c}+k f_{c} \frac{\mathrm{d} f_{c}}{\mathrm{~d} e_{1}} f_{c} \operatorname{sgn}\left(e_{1}\right) \\
\leq & \frac{\partial h_{c}}{\partial e_{1}} h_{c}^{2}+\left(k^{2} f_{c} h_{c}+f_{c} h_{c}+k f_{c}^{2}\right)\left|\frac{\mathrm{d} f_{c}}{\mathrm{~d} e_{1}}\right| .
\end{aligned}
$$

Since

$$
\begin{aligned}
\beta_{01}^{2} & >\frac{4 \beta_{02}}{g_{1}^{\prime}}\left|\left(\frac{g_{2}}{g_{1}^{\prime}}\right)^{\prime}\right|>\frac{(k+1)^{2} \beta_{02}}{k g_{1}^{\prime}}\left|\left[\frac{g_{2}}{g_{1}^{\prime}}\right]^{\prime}\right| \\
& =\frac{(k+1)^{2} \beta_{01}}{g_{1}^{\prime}}\left|\frac{\mathrm{d} f_{c}}{\mathrm{~d} e_{1}}\right|
\end{aligned}
$$

then

$$
\begin{aligned}
\frac{\partial h_{c}}{\partial e_{1}} & =-\beta_{01} g_{1}^{\prime}+k \frac{\mathrm{d}\left(f_{c} \operatorname{sgn}\left(e_{1}\right)\right)}{\mathrm{d} e_{1}} \\
& <-(k+1)^{2}\left|\frac{\mathrm{d} f_{c}}{\mathrm{~d} e_{1}}\right|+k\left|\frac{\mathrm{d} f_{c}}{\mathrm{~d} e_{1}}\right|<0 .
\end{aligned}
$$

We can obtain that

$$
\begin{aligned}
\left|\frac{\partial h_{c}}{\partial e_{1}}\right| & =\left|-\beta_{01} g_{1}^{\prime}+k \frac{\mathrm{d}\left(f_{c} \operatorname{sgn}\left(e_{1}\right)\right)}{\mathrm{d} e_{1}}\right| \\
& >\beta_{01} g_{1}^{\prime}-k\left|\frac{\mathrm{d} f_{c}}{\mathrm{~d} e_{1}}\right| .
\end{aligned}
$$

Based on (25), we have

$$
\beta_{01} g_{1}^{\prime}>(k+1)^{2}\left|\frac{\mathrm{d} f_{c}}{\mathrm{~d} e_{1}}\right| .
$$

Substituting (28) into (27) yields

$$
\begin{aligned}
\left|\frac{\partial h_{c}}{\partial e_{1}}\right| & >\beta_{01} g_{1}^{\prime}-k\left|\frac{\mathrm{d} f_{c}}{\mathrm{~d} e_{1}}\right|>(k+1)^{2}\left|\frac{\mathrm{d} f_{c}}{\mathrm{~d} e_{1}}\right|-k\left|\frac{\mathrm{d} f_{c}}{\mathrm{~d} e_{1}}\right| \\
& =\left(k^{2}+k+1\right)\left|\frac{\mathrm{d} f_{c}}{\mathrm{~d} e_{1}}\right| .
\end{aligned}
$$

Furthermore,

$$
\begin{aligned}
\left|\frac{\partial h_{c}}{\partial e_{1}}\right| h_{c}^{2} & >\left(k^{2} h_{c}^{2}+k h_{c}^{2}+h_{c}^{2}\right)\left|\frac{\mathrm{d} f_{c}}{\mathrm{~d} e_{1}}\right| \\
& >\left(k^{2} f_{c} h_{c}+f_{c} h_{c}+k f_{c}^{2}\right)\left|\frac{\mathrm{d} f_{c}}{\mathrm{~d} e_{1}}\right| .
\end{aligned}
$$

According to (24) and (30), we can obtain that

$$
\dot{V}_{2}<0 \text {. }
$$

Thus, the error of the observer will converge to zero, that is, $e_{1}(t) \rightarrow 0, e_{2}(t) \rightarrow 0(t \rightarrow \infty)$. This completes the proof.

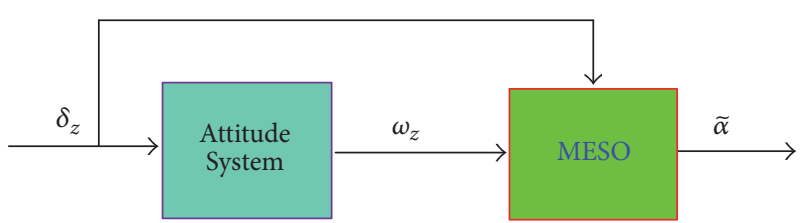

Figure 2: The structure of AOA reconstruction.

In terms of (11)-(12), the functions $g_{i}\left(e_{1}\right)$ are

$$
\begin{aligned}
& g_{1}\left(e_{1}\right)=e_{1} \\
& g_{2}\left(e_{1}\right)=p e_{1}+q e_{1}^{2}+r\left(1-\exp \left(e_{1}\right)\right) .
\end{aligned}
$$

According to Lemma 2, the self-stable condition of (15) is

$$
\begin{gathered}
f_{c}\left(e_{1}\right)=\frac{\beta_{02}\left|p e_{1}+q e_{1}^{2}+r\left(1-\exp \left(e_{1}\right)\right)\right|}{k \beta_{01}}, \\
\beta_{01}^{2}>4 \beta_{02}\left|p+2 q e_{1}-r \cdot \exp \left(e_{1}\right)\right| .
\end{gathered}
$$

Therefore, the MESO can be employed to estimate the total disturbances and reconstruct the unmeasured AOA.

\section{Control System Design}

In this section, a robust control method is proposed based on the ADRC technique to handle parameter uncertainties and external disturbances. It is assumed that the attitude had been adjusted to the command value when velocity control design is proceeding; that is, the velocity is mainly related to fuel mass flow $m_{c}$ since the thrust force $T$ is affected by $\alpha$. Additionally, AOA reconstruction method is developed by using the available input/output information of attitude system via MESO.

4.1. AOA Reconstruction. Practically, the deflection of the control surface $\delta_{z}$ and the pitch rate $\omega_{z}$ are measurable, but the AOA $\alpha$ is difficult to be precisely measured. To address this problem, the modified extended state observer technique is introduced into the design of the reconstruction for AOA. From the AOA reconstruction depicted in Figure 2, it can be seen that this strategy only needs the information of the measured $\delta_{z}$ and $\omega_{z}$.

The AOA reconstruction based on the MESO is formulated as

$$
\begin{aligned}
e & =z_{1}-\omega_{z} \\
\dot{z}_{1} & =f_{4}+g_{4} \delta_{z}-\beta_{01} e \\
\dot{z}_{2} & =z_{3}-\beta_{02} \mathrm{fal}_{2}(e, a, \delta)+z_{1} \\
\dot{z}_{3} & =-\beta_{03} \mathrm{fal}_{2}(e, a, \delta),
\end{aligned}
$$


where $\beta_{0 i}(i=1,2,3)$ is the observer gain. If $\beta_{0 i}$ is chosen appropriately, the state variables of MESO will converge as follows:

$$
\begin{aligned}
& z_{1} \longrightarrow \omega_{z}, \\
& z_{2} \longrightarrow \alpha, \\
& z_{3} \longrightarrow-f_{2} .
\end{aligned}
$$

Obviously, $\alpha$ is reconstructed by $z_{2}$ without $f_{2}$; that is, $\tilde{\alpha}=z_{2}$. Thus, the reconstruction $z_{2}$ can be used in the velocity system instead of the measured AOA.

4.2. Velocity Controller Design. In this subsection, the ADRC is designed for the velocity control of nonlinear ASV system in the presence of uncertainties and disturbances. From the structure of the ADRC for ASV velocity control shown in Figure 3, it can be seen that the ADRC system mainly includes three parts. In part 1, MESO is designed to estimate the total disturbances. Then, a nonlinear state error feedback (NLSEF) law is conducted to obtain the initial control law $u_{0}$ according to the error between state values and command values in part 2 , and the velocity control law $u$ is implemented by augmenting the NLSEF law $u_{0}$ with the disturbance compensation $z_{v 2}$ which is completed by MESO in part 3.

In this way, the velocity can be controlled in set value, and the ADRC design procedure of velocity control is presented in detail as follows.

4.2.1. Total Disturbance Estimation. The key of this design is to interpret the total disturbance including the uncertainties and disturbances as an additional state to be estimated. Different from the traditional ADRC, the MESO with the modified smooth function $\mathrm{fal}_{2}\left(e_{1}, a, \delta\right)$ is adopted to estimate the total disturbances $d_{t}$. For this purpose, we add an extended state $x_{5}$ as the total disturbance $d_{t}$ which is calculated by (6), and then the velocity system is rewritten as

$$
\begin{aligned}
& \dot{x}_{1}=f_{1}+u_{v}+x_{5} \\
& \dot{x}_{5}=h(t),
\end{aligned}
$$

where $u_{v}=g_{1} m_{c}$ and the function $h(t)$ is the derivative of $d_{t}$, which is unknown and bounded. Then a second-order MESO is proposed as

$$
\begin{gathered}
e_{1}=z_{v 1}-x_{1} \\
\dot{z}_{v 1}=z_{v 2}-\beta_{01} e_{1}+f_{1}+u_{v} \\
\dot{z}_{v 2}=-\beta_{02} \mathrm{fal}_{2}\left(e_{1}, a, \delta\right),
\end{gathered}
$$

where the observer gains are $\beta_{01}>0, \beta_{02}>0$, and corresponding to (24) the stability condition of MESO is satisfied. That is, $z_{v 1} \rightarrow x_{1}, z_{v 2} \rightarrow d_{t}$ can be guaranteed in finite time. In this case, $z_{v 2}$ is the estimated value of the total disturbances; that is, the estimated errors can converge to zero in finite time. This indicates that an improved tracking performance can be achieved by using the estimated state $z_{v 2}$ in the controller design to compensate for the total disturbances $d_{t}$.
4.2.2. Nonlinear State Error Feedback Law. A nonlinear feedback control law is the nonlinear combination of the errors between the command and the real state. Here, by introducing $\mathrm{fal}_{2}\left(e_{1}, a, \delta\right)$, the feedback control law is selected as

$$
\begin{gathered}
e_{2}=x_{1}^{*}-x_{1} \\
u_{v 0}=b \mathrm{fal}_{2}\left(e_{2}, a, \delta\right),
\end{gathered}
$$

where $x_{1}^{*}=V_{c}$ is the velocity command and $b$ is the ADRC parameter.

4.2.3. Disturbance Dynamic Compensation. In order to reduce the influence of the disturbances, the disturbance dynamics need to be substituted into the control law based on the estimated state $z_{v 2}$ which is obtained by the MESO. According to the structure of ADRC, the final control law of system (36) can be expressed as

$$
u_{v}=u_{v 0}-f_{1}-z_{v 2}
$$

Then the control

$$
m_{c}=\frac{\left(u_{v 0}-z_{v 2}-f_{1}\right)}{g_{1}} .
$$

4.3. Stability Analysis. This subsection will study the stability and the convergence of the closed-loop system. Define the estimation errors of total disturbance

$$
e_{3}=z_{v 2}-d_{t}
$$

Substituting (39) into (36), then the velocity control system is rewritten as

$$
\begin{aligned}
\dot{x}_{1} & =f_{1}+u_{v}+d_{t}=f_{1}+\left(u_{v 0}-f_{1}-z_{v 2}\right)+d_{t} \\
& =u_{v 0}-e_{3} .
\end{aligned}
$$

Choose the following Lyapunov function:

$$
V_{3}=\frac{1}{2}\left(x_{1}^{*}-x_{1}\right)^{2}
$$

Then calculate the time derivate of $V_{3}$; that is,

$$
\begin{aligned}
\dot{V}_{3} & =\left(\dot{x}_{1}^{*}-\dot{x}_{1}\right)\left(x_{1}^{*}-x_{1}\right)=\left(\dot{x}_{1}^{*}+e_{3}-u_{v 0}\right)\left(x_{1}^{*}-x_{1}\right) \\
& =-u_{v 0}\left(x_{1}^{*}-x_{1}\right)+\left(\dot{x}_{1}^{*}+e_{3}\right)\left(x_{1}^{*}-x_{1}\right) \\
& =b \mathrm{fal}_{2}\left(\left(x_{1}^{*}-x_{1}\right), a, \delta\right)+\left(\dot{x}_{1}^{*}+e_{3}\right)\left(x_{1}^{*}-x_{1}\right) \\
& =-b\left|x_{1}^{*}-x_{1}\right|^{a+1}+\left(\dot{x}_{1}^{*}+e_{3}\right)\left(x_{1}^{*}-x_{1}\right) .
\end{aligned}
$$

If $|b|\left|x_{1}^{*}-x_{1}\right|^{a} \geq\left|e_{3}+\dot{x}_{1}^{*}\right|$, then $\dot{V}_{3} \leq 0$ is satisfied; that is, the control system is stable.

\section{Simulation Results and Discussions}

In this section, a numerical simulation is conducted to illustrate the effectiveness of the control method and the state 


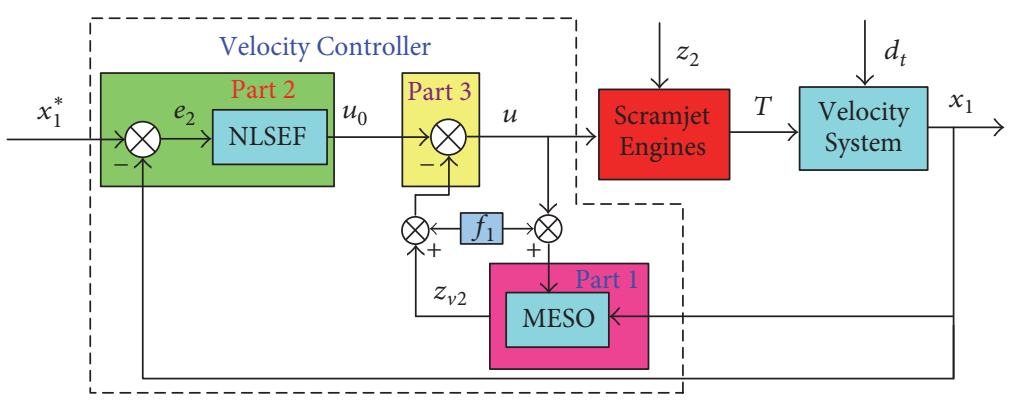

FIgURE 3: The structure of the ADRC.

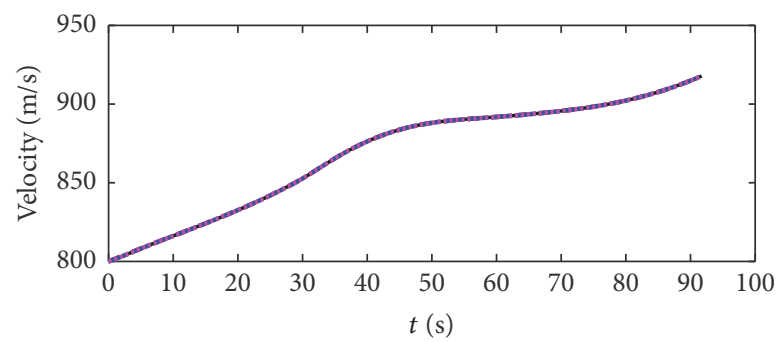

$$
\begin{aligned}
& \text { - - - } V_{\text {ref }} \quad \text {----- } V \text {-Case } 2 \\
& \text { - } V \text {-Case } 1 \quad \text {.......... } V \text {-Case } 3
\end{aligned}
$$

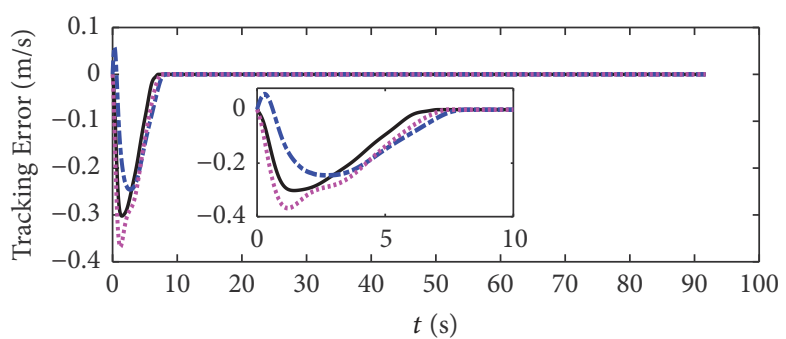

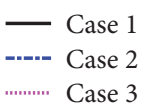

FIGURE 4: Velocity tracking and tracking error.

TABLE 1: Parameter uncertainties of different cases.

\begin{tabular}{lcccc}
\hline Case & $\Delta C_{D}$ & $\Delta C_{L}$ & $\Delta \rho$ & $d\left(\mathrm{~m} / \mathrm{s}^{2}\right)$ \\
\hline 1 & 0 & 0 & 0 & 0 \\
2 & $-20 \%$ & $+5 \%$ & $+3 \%$ & $+2.5 \sin (0.1 \pi t)$ \\
3 & $+20 \%$ & $-5 \%$ & $-3 \%$ & $-2.5 \sin (0.1 \pi t)$ \\
\hline
\end{tabular}

reconstruction strategy. In order to show the performance improvement of the MESO, the total disturbances of the system are estimated by comparing with TESO method. Three conditions with uncertainties and external disturbance are listed in Table 1.

Here, the initial values of velocity $V, \theta, h$, and $m$ are set to be $V(0)=800 \mathrm{~m} / \mathrm{s}, \theta(0)=0 \mathrm{deg}, h(0)=15 \mathrm{~km}$, and $m(0)=$ $500 \mathrm{~kg}$. The controller parameters are given in Table 2, and the simulation results are presented in Figures 4-13.

As shown in Figure 4, the system state $V$ can accurately and quickly track the given command. Moreover, the
TABLE 2: Control parameters.

\begin{tabular}{lcccccr}
\hline $\begin{array}{l}\text { ADRC } \\
\text { parameter }\end{array}$ & $\beta_{01}$ & $\beta_{02}$ & $\beta_{03}$ & $a$ & $\delta$ & $b$ \\
\hline Value & 100 & 300 & 1000 & 0.5 & 0.01 & 4 \\
\hline
\end{tabular}

tracking error remains remarkably small and converges to zero asymptotically in all cases; that is, a fairly satisfactory tracking error response is achieved with no steady-state error, which indicates the effectiveness of the suggested control method. Figures 5 and 6 show that the AOA reconstruction error rapidly converges to zero with a maximal error about $0.1^{\circ}$, which indicates that the developed state reconstruction method is efficient by using the MESO. From the altitude and flight-path angle histories presented in Figures 7 and 8, it is apparent that there are no significant differences among the listed cases. Notably the control $m_{c}$ is fairly smooth without chattering phenomenon (see Figure 9). From Figures 

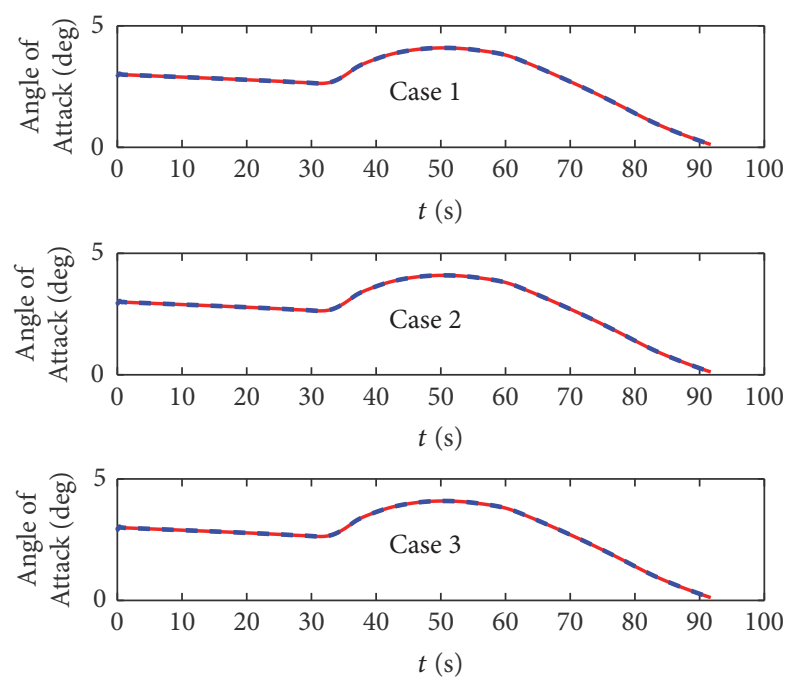

- True $\alpha$

- - Reconstructed $\alpha$

FIGURE 5: Reconstruction of angle of attack.

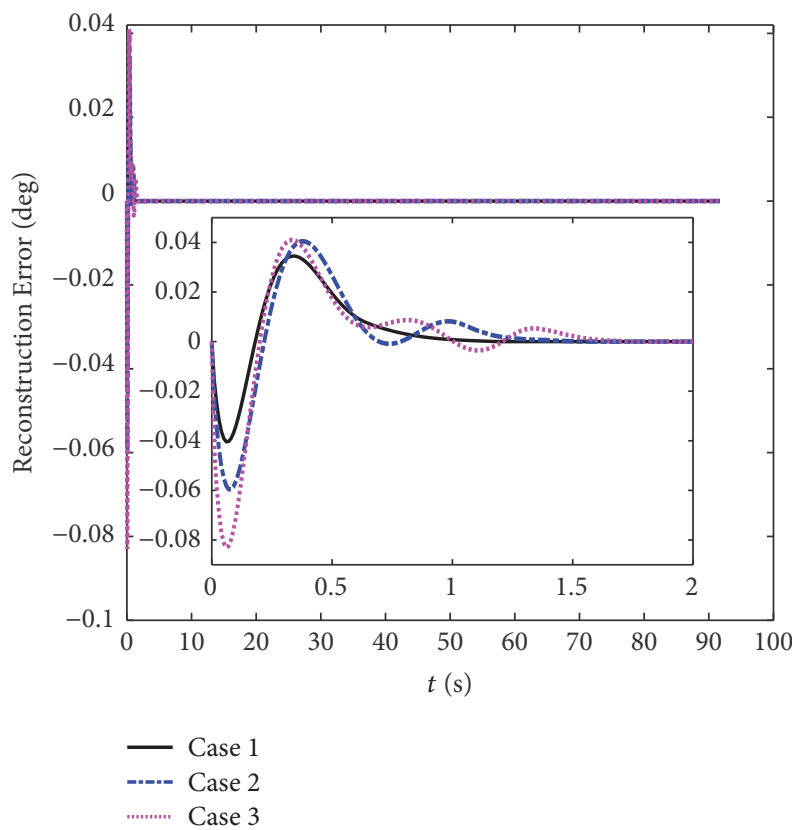

FIgURE 6: The reconstruction error of angle of attack.

10-13, it is shown that the suggested MESO can estimate the total disturbances. Meanwhile, a fairly satisfactory estimation error response is achieved, while both the transient and steady-state performance are retained with the MESO. Also it is found that TESO leads to significant estimation steady-state error, and the convergence rate is slower than that of MESO. Furthermore, the influence of uncertainties and disturbances in the flight control system is inhibited by compensating the estimated value into the control system, which is owing to the precise and rapid estimation of the total disturbances via MESO. Consequently, the simulation results demonstrate

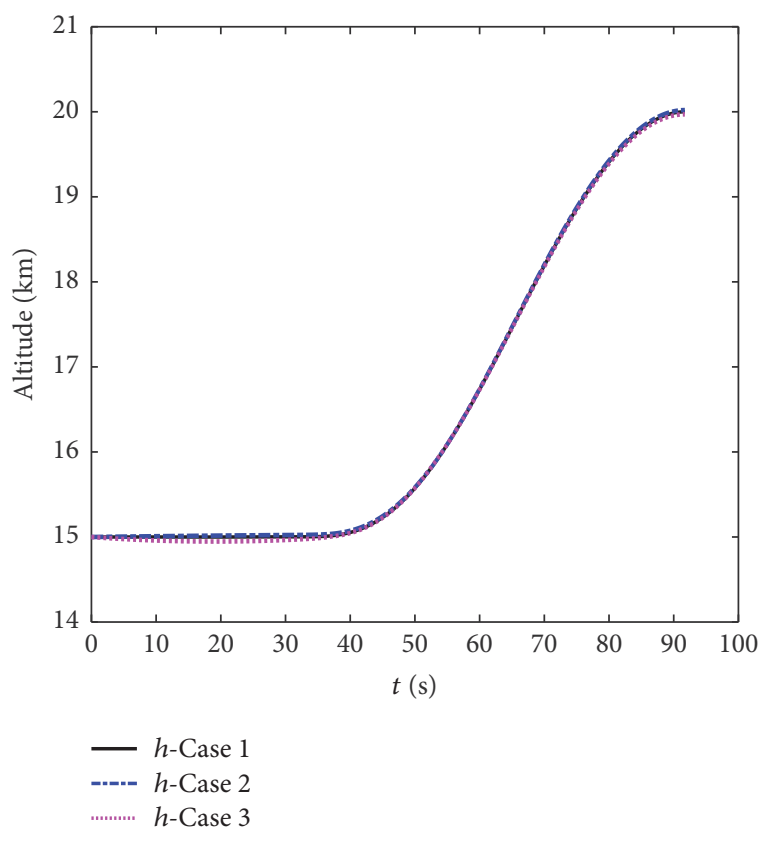

FIgURE 7: Variation of the altitude.

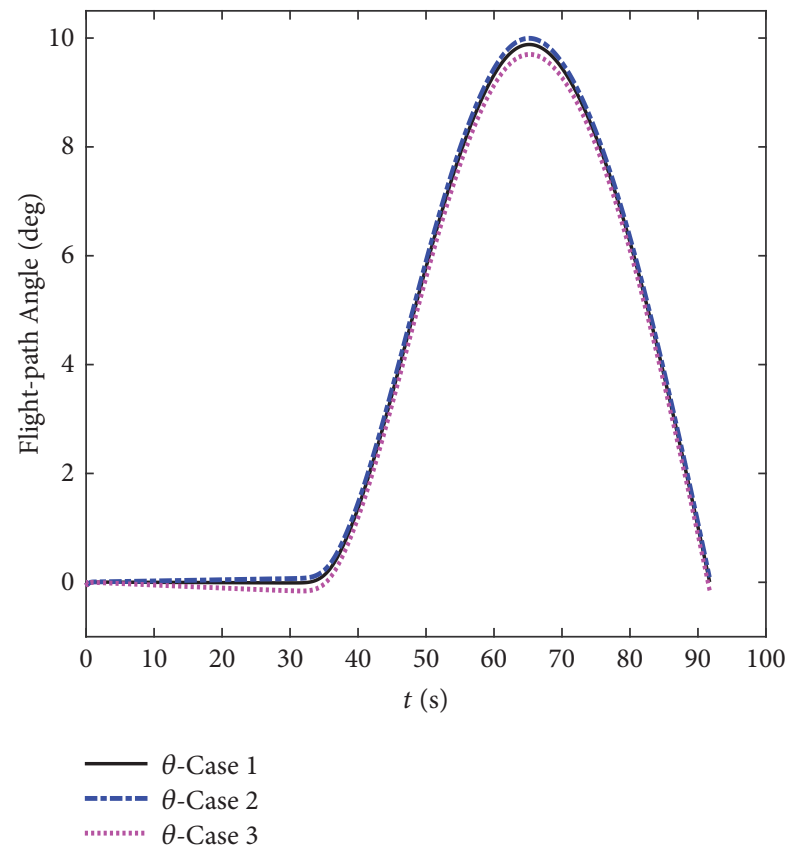

Figure 8: Variation of the flight-path angle.

that the proposed control scheme achieves good velocity tracking performance and enhanced robustness against parameter uncertainties and external disturbances.

\section{Conclusions}

In this paper, a novel robust controller is addressed for the velocity system of a generic ASV. A MESO is proposed by 


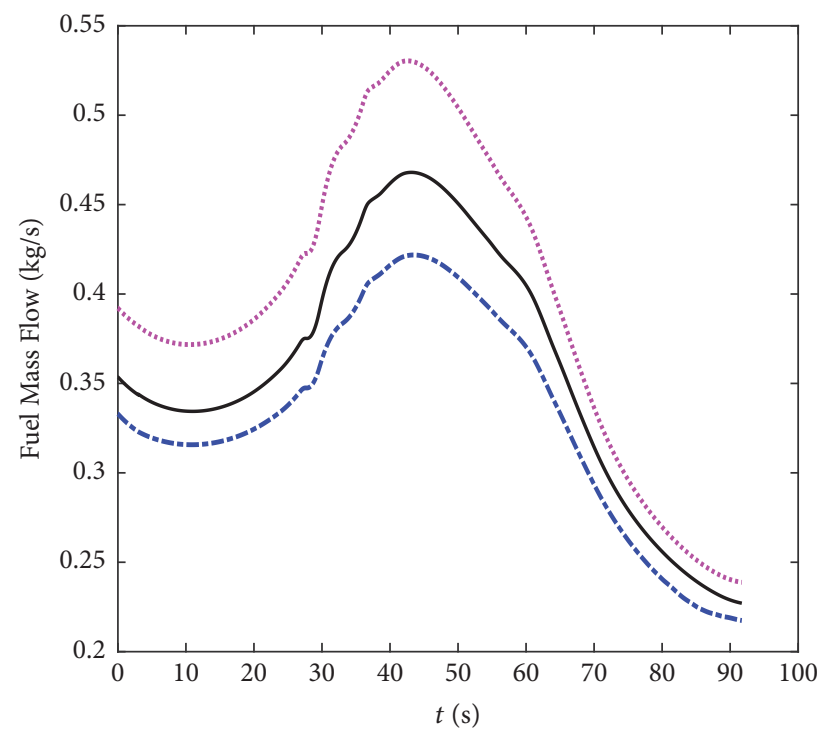

$m_{c}$-Case 1

-.--- $m_{c}$-Case 2

........... $m_{c}$-Case 3

FIgURE 9: Variation of the fuel mass flow.

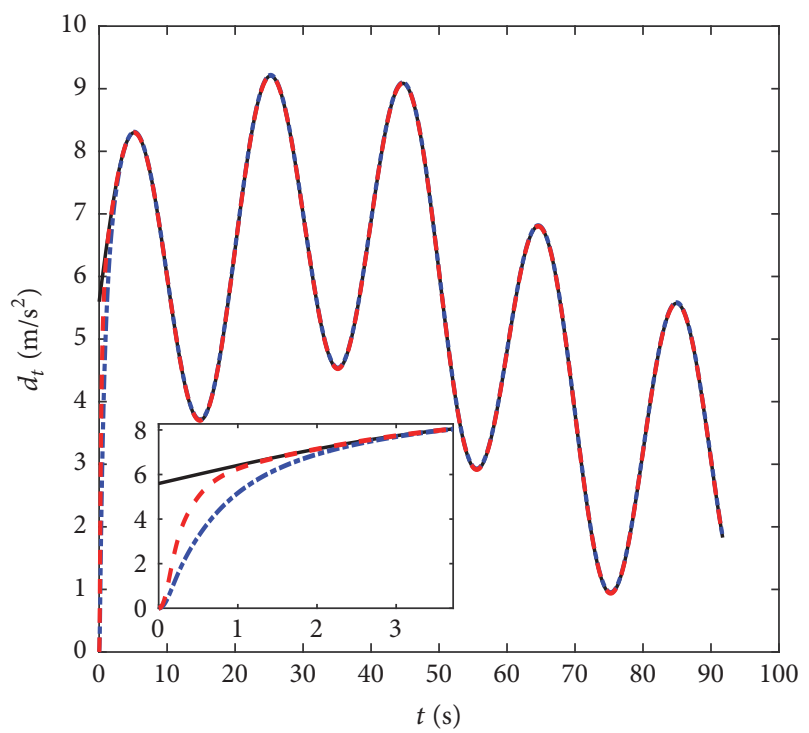

- Actual-Case 2

-.--- Estimate TESO-Case 2

- - - Estimate MESO-Case 2

FIGURE 10: Estimations of the total disturbances.

developing a new smooth function to replace the traditional nonderivable function. Then an ADRC technique is introduced to track the desired velocity by using the MESO to estimate and compensate the total disturbance so as to improve the robustness performance against the parameters uncertainties and external disturbances. Additionally, a state reconstruction method by utilizing the available input/output information is presented based on the MESO to reconstruct the unmeasured AOA. Simulation results demonstrate the

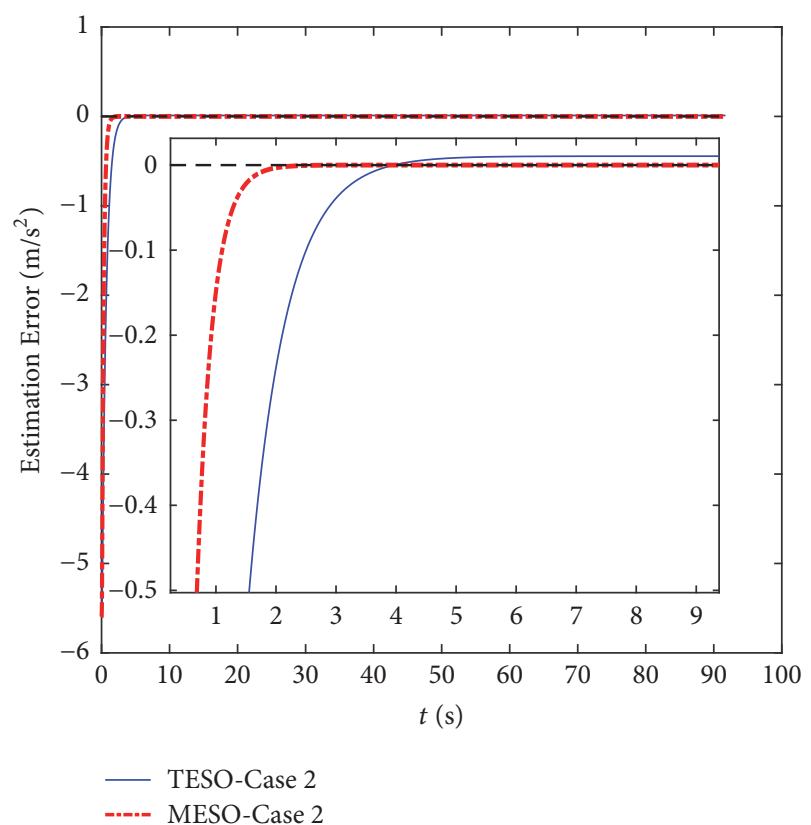

FIGURE 11: Estimation error of the total disturbances.

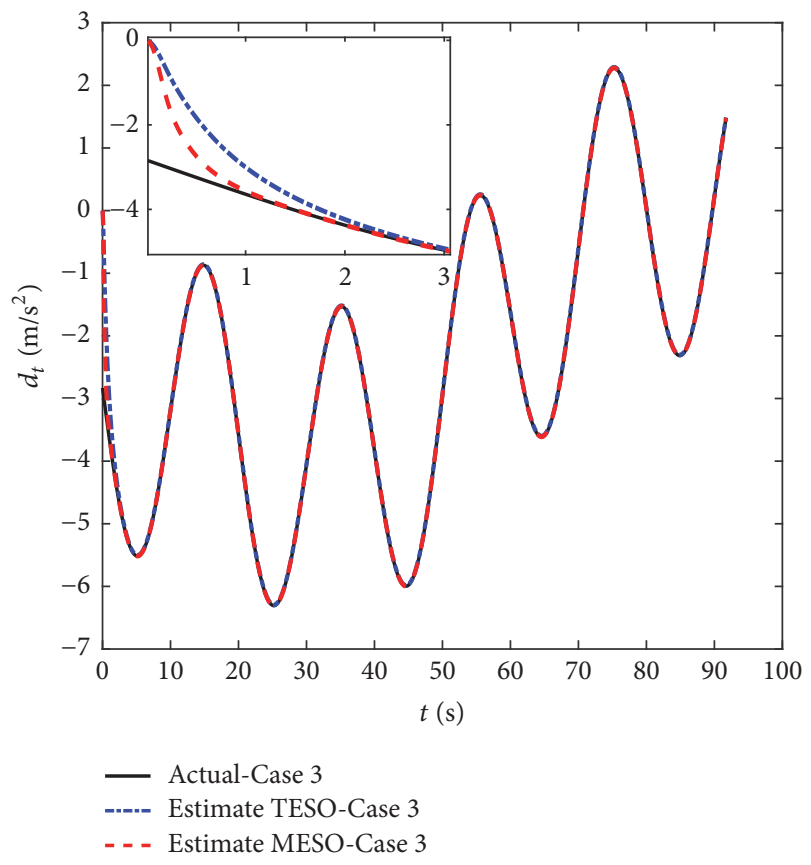

FIGURE 12: Estimations of the total disturbances.

effectiveness of the suggested control approach. The extension of presented control method to a flexible ASV and the influence of structural flexibility on control system will be potential areas of further research.

\section{Data Availability}

The data used to support the findings of this study are available from the corresponding author upon request. 


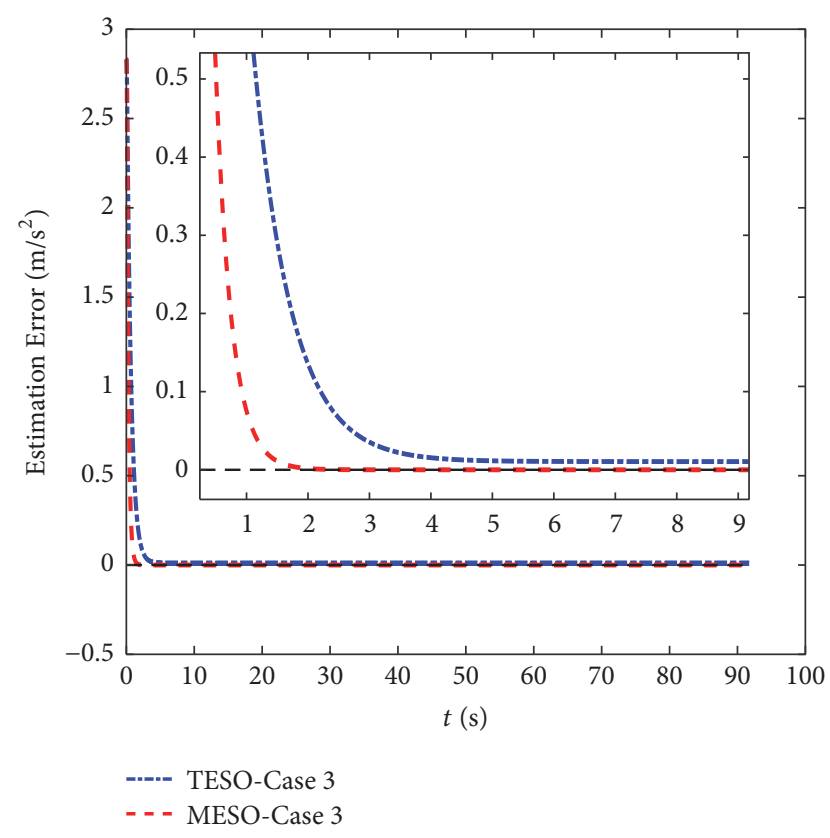

FIGURE 13: Estimation error of the total disturbances.

\section{Conflicts of Interest}

The authors declare that there are no conflicts of interest regarding the publication of this article.

\section{Acknowledgments}

This work was supported by the National Natural Science Foundation of China [11176012].

\section{References}

[1] M. A. Bolender, "An overview on dynamics and controls modeling of hypersonic vehicles," in Proceedings of the American Control Conference, Hyatt Regency Riverfront, pp. 2507-2512, St Louis, MO, USA, 2009.

[2] J. Wang, Q. Zong, R. Su, and B. Tian, "Continuous high order sliding mode controller design for a flexible air-breathing hypersonic vehicle," ISA Transactions ${ }^{\circledR}$, vol. 53, no. 3, pp. 690-698, 2014.

[3] O. Ur Rehman, I. R. Petersen, and B. Fidan, "Feedback linearization-based robust nonlinear control design for hypersonic flight vehicles," Proceedings of the Institution of Mechanical Engineers, Part I: Journal of Systems and Control Engineering, vol. 227, no. 1, pp. 3-11, 2013.

[4] Y. Ji, Q. Zong, and H. Zhou, "Command filtered back-stepping control of a flexible air-breathing hypersonic flight vehicle," Proceedings of the Institution of Mechanical Engineers, Part G: Journal of Aerospace Engineering, vol. 228, no. 9, pp. 1617-1626, 2014.

[5] R. Sun, J. Na, and B. Zhu, "Robust approximation-free prescribed performance control for nonlinear systems and its application," International Journal of Systems Science, vol. 49, no. 3, pp. 511-522, 2018.

[6] J. Na, G. Herrmann, and K. Zhang, "Improving transient performance of adaptive control via a modified reference model and novel adaption," International Journal of Robust and Nonlinear Control, vol. 27, no. 8, pp. 1351-1372, 2017.

[7] X. Hu, L. Wu, C. Hu, and H. Gao, "Adaptive sliding mode tracking control for a flexible air-breathing hypersonic vehicle," Journal of The Franklin Institute, vol. 349, no. 2, pp. 559-577, 2012.

[8] J. Na, X. Ren, and D. Zheng, "Adaptive control for nonlinear pure-feedback systems with high-order sliding mode observer," IEEE Transactions on Neural Networks and Learning Systems, vol. 24, no. 3, pp. 370-382, 2013.

[9] Y. Huang and W. Xue, "Active disturbance rejection control: methodology and theoretical analysis," ISA Transactions ${ }^{\circledR}$, vol. 53, no. 4, pp. 963-976, 2014.

[10] R. Parvathy and A. E. Daniel, "A survey on active disturbance rejection control," in Proceedings of the 2013 International MultiConference on Automation, Computing, Communication, Control and Compressed Sensing (iMac4s), pp. 330-335, Kottayam, India, March 2013.

[11] Q. Zheng and Z. Q. Gao, "Motion control design optimization: problem and solutions," International Journal of Intelligent Control and Systems, vol. 10, pp. 269-276, 2005.

[12] Q. Chen, L. Li, M. Wang, and L. Pei, “The precise modeling and active disturbance rejection control of voice coil motor in high precision motion control system," Applied Mathematical Modelling, vol. 39, no. 19, pp. 5936-5948, 2015.

[13] L. Dong, Q. Zheng, and Z. Gao, "On control system design for the conventional mode of operation of vibrational gyroscopes," IEEE Sensors Journal, vol. 8, no. 11, pp. 1871-1878, 2008.

[14] Q. Zheng and Z. Q. Gao, "Disturbances rejection in MEMS gyroscopes: problem and solutions," in Proceedings of the 30th Chinese Control Conference, pp. 6334-6339, Yantai, China, 2011.

[15] M. You-jie, Y. Yang, Z. Xue-song, and L. Chao, "Control technology of maximal wind energy capture of VSCF wind power generation," in Proceedings of the 2010 WASE International Conference on Information Engineering (ICIE), pp. 268-271, Beidaihe, China, August 2010.

[16] Y. Tang, Y. Bai, C. Huang, and B. Du, "Linear active disturbance rejection-based load frequency control concerning high penetration of wind energy," Energy Conversion and Management, vol. 95, pp. 259-271, 2015.

[17] R. Jiuhong, R. Xuewen, and W. Sanyou, "Study on ADRC controller design and simulation of rock drill robot joint hydraulic drive system," in Proceedings of the 2007 Chinese Control Conference, pp. 133-136, Zhangjiajie, China, July 2007.

[18] R. Song, Y. Li, J. Ruan, and J. Huang, "Study on ADRC-based mobile robot lateral control," in Proceedings of the 2007 IEEE International Conference on Robotics and biomimetics (ROBIO), pp. 1190-1193, Sanya, China, December 2007.

[19] C. Qin, N. Qi, R. Lü, and K. Zhu, "ADRC fractional order PID controller design of hypersonic flight vehicle," Transactions of Nanjing University of Aeronautics and Astronautics, vol. 28, no. 3, pp. 240-245, 2011.

[20] J. Song, L. Wang, G. Cai, and X. Qi, "Nonlinear fractional order proportion-integral-derivative active disturbance rejection control method design for hypersonic vehicle attitude control," Acta Astronautica, vol. 111, Article ID 5364, pp. 160-169, 2015.

[21] X. Shao and H. Wang, "Active disturbance rejection based trajectory linearization control for hypersonic reentry vehicle with bounded uncertainties," ISA Transactions ${ }^{\circledR}$, vol. 54, pp. 2738, 2015. 
[22] D. K. Kori, J. P. Kolhe, and S. E. Talole, "Extended state observer based robust control of wing rock motion," Aerospace Science and Technology, vol. 33, no. 1, pp. 107-117, 2014.

[23] Q. Zheng, L. Q. Gao, and Z. Gao, "On validation of extended state observer through analysis and experimentation," Journal of Dynamic Systems, Measurement, and Control, vol. 134, no. 2, Article ID 024505, 2012.

[24] N. M. Qi, C. M. Qin, and Z. G. Song, "Improved ADRC cascade decoupling controller design of hypersonic vehicle," Journal of Harbin Institute of Technology, vol. 43, no. 11, pp. 34-38, 2011.

[25] M. A. Bolender and D. B. Doman, "Nonlinear longitudinal dynamical model of an air-breathing hypersonic vehicle," Journal of Spacecraft and Rockets, vol. 44, no. 2, pp. 374-387, 2007.

[26] J. Yao, Z. Jiao, and D. Ma, "Adaptive robust control of dc motors with extended state observer," IEEE Transactions on Industrial Electronics, vol. 61, no. 7, pp. 3630-3637, 2014.

[27] Y. Huang and J. Han, "Analysis and design for the second order nonlinear continuous extended states observer," Chinese Science Bulletin, vol. 45, no. 21, pp. 1938-1944, 2000. 


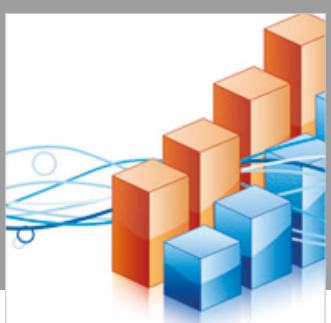

Advances in

Operations Research

\section{-n-m}
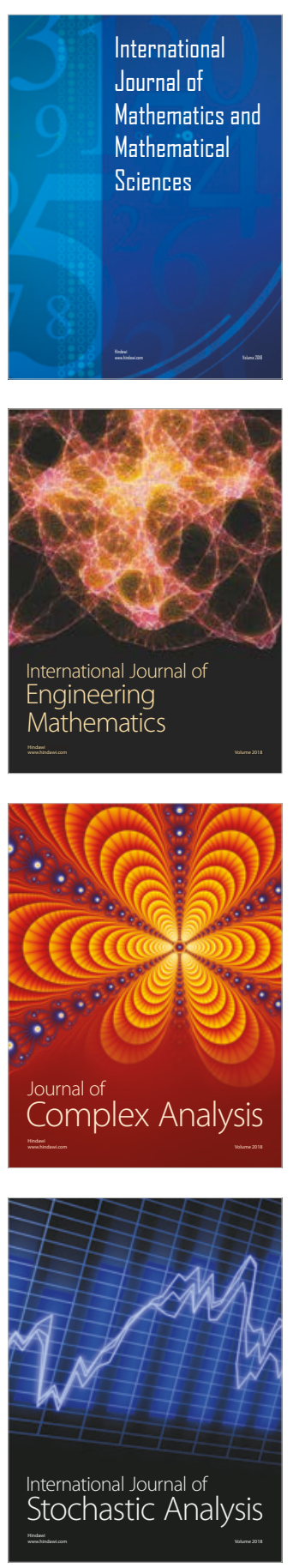
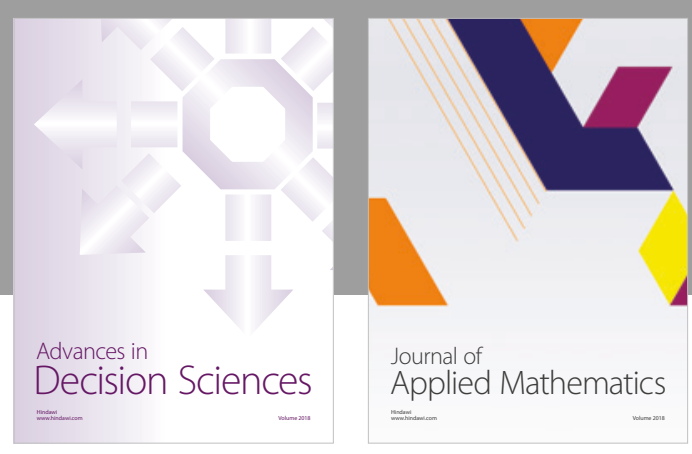

Journal of

Applied Mathematics
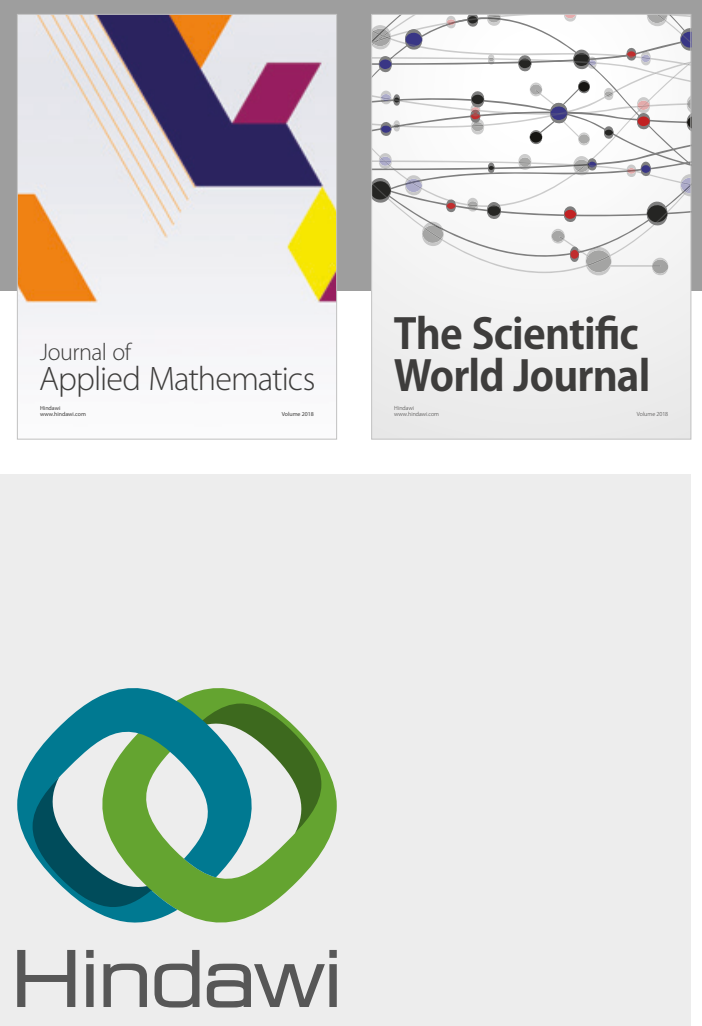

Submit your manuscripts at

www.hindawi.com

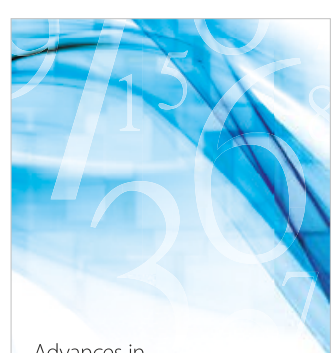

Advances in
Numerical Analysis
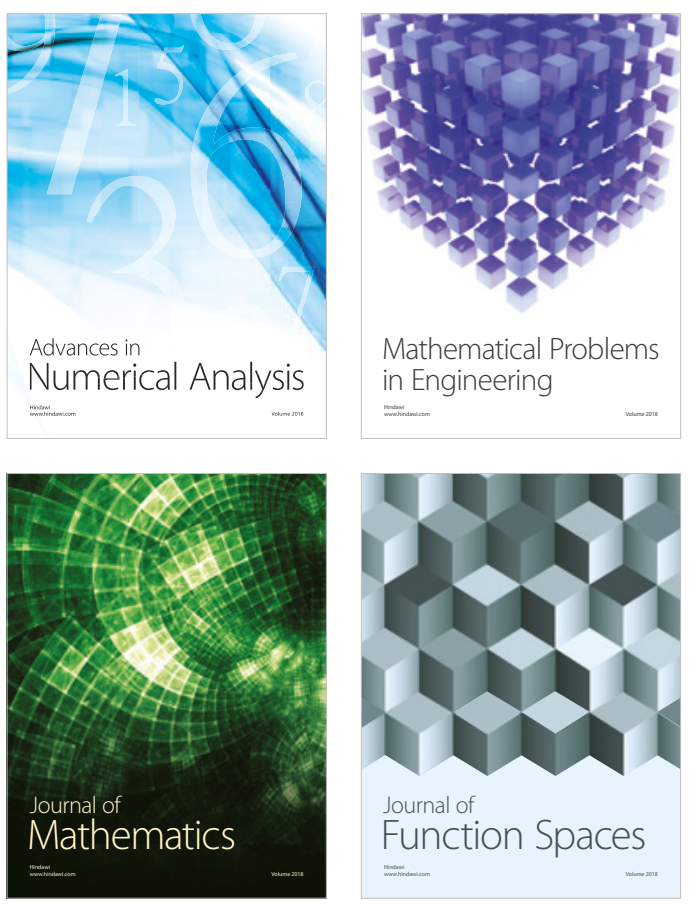

Mathematical Problems in Engineering

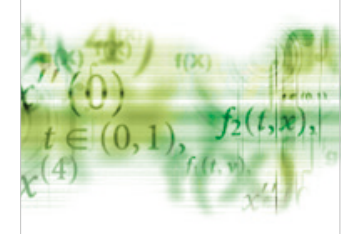

International Journal of

Differential Equations

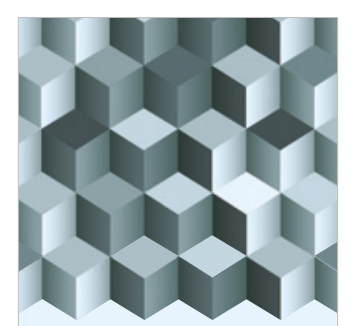

Journal of

Function Spaces
The Scientific

World Journal

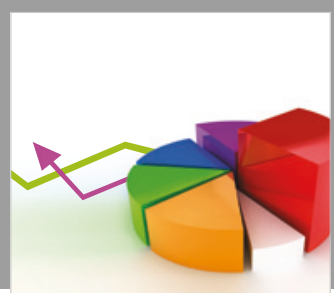

Journal of

Probability and Statistics
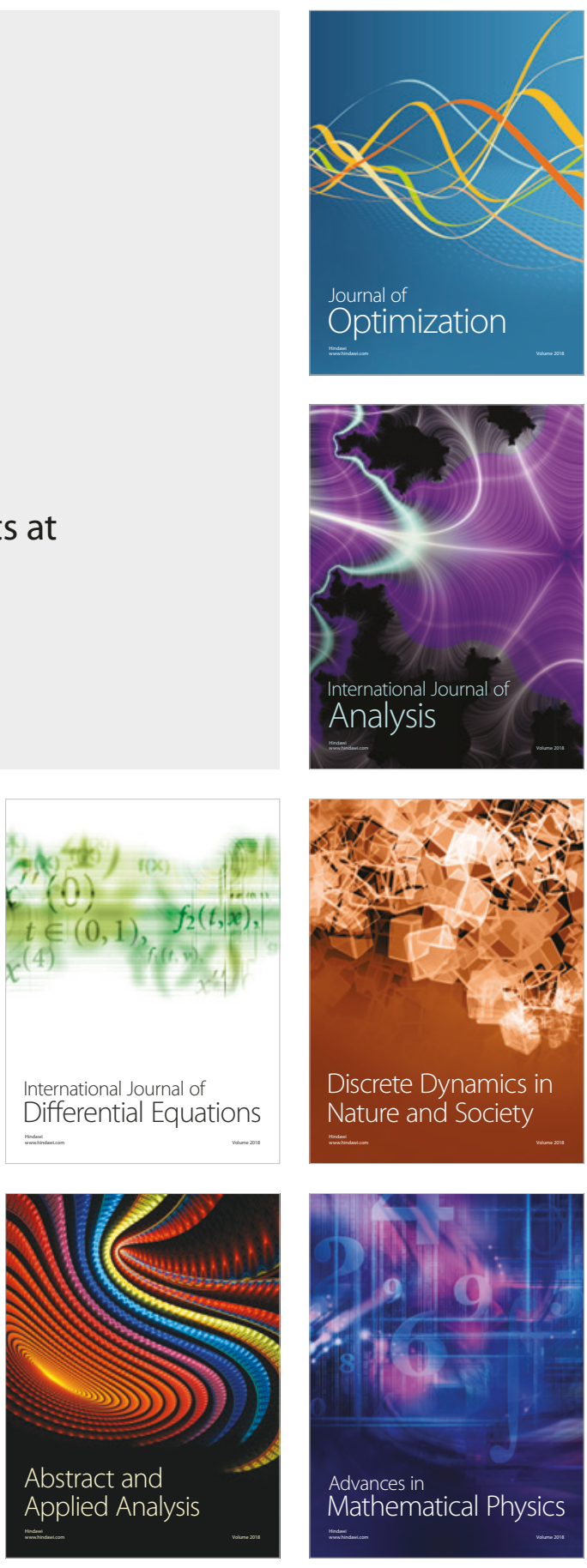